\title{
Gastrocolocutaneous fistula: An unusual complication of percutaneous endoscopic gastrostomy
}

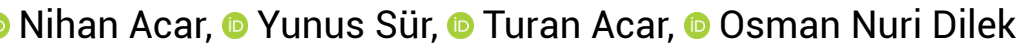 \\ Department of General Surgery, İzmir Katip Çelebi University Atatürk Training and Research Hospital, İzmir, Turkey
}

\begin{abstract}
Gastrocolocutaneous fistula is a rare potential complication of percutaneous endoscopic gastrostomy (PEG). This case report is a description of the approach used to manage a gastrocolocutaneous fistula that developed after a PEG procedure. A 35-year-old male with amyotrophic lateral sclerosis had a PEG tube inserted in the endoscopy unit due to recurrent episodes of aspiration pneumonia. During the postoperative period, the PEG tube was withdrawn as a result of bilious discharge from the rim of the tube and maceration of the skin around the tube The patient was referred to us due to the leakage of feces from the PEG site. Given the high rate of flow observed during follow-up and the unlikelihood of spontaneous closure, surgical repair was planned. The operation included repair of a fistula between the stomach and the colon, partial gastric resection, and primary sutures to effect a repair of the colon. Proper management of complications of a PEG procedure can lead to a quick and effective recovery.

Keywords: Complication; gastrocolocutaneous fistula; percutaneous endoscopic gastrostomy.
\end{abstract}

\section{Introduction}

Percutaneous endoscopic gastrostomy (PEG) is a safe and effective method for providing long-term enteral nutrition. ${ }^{[1]}$ However, previous studies have reported some probable complications such as wound infection, tube dislodgement, peristomal leakage, bleeding, internal organ injury, necrotizing fasciitis, and aspiration pneumonia. ${ }^{[2,3]}$ Most complications are minor, but some rare severe complications may be life threatening. Gastrocolocutaneous fistula is a rare complication of percutaneous endoscopic gastrostomy (PEG). ${ }^{[4]}$ In this case, we aimed to present our approach to the gastrocolocutaneous fistula developed after PEG.

\section{Case Report}

A 35-year-old male with Amyotrophic Lateral Sclerosis (ALS) had a PEG tube inserted in the endoscopy unit due to recurrent aspiration pneumonia episodes. He had not undergone abdominal surgery. In postoperative 5th day, PEG was withdrawn when he developed bilious discharge from the rim of the tube and maceration on the skin around the tube. A new PEG tube was inserted after the wound care. He was referred to general surgery clinic when feces were started to leak from the former PEG site. The abdominal computed tomography (CT) demonstrated the signs of gastrocolocutaneous fistula (Fig. 1). After the patient was transferred to our clinic, 


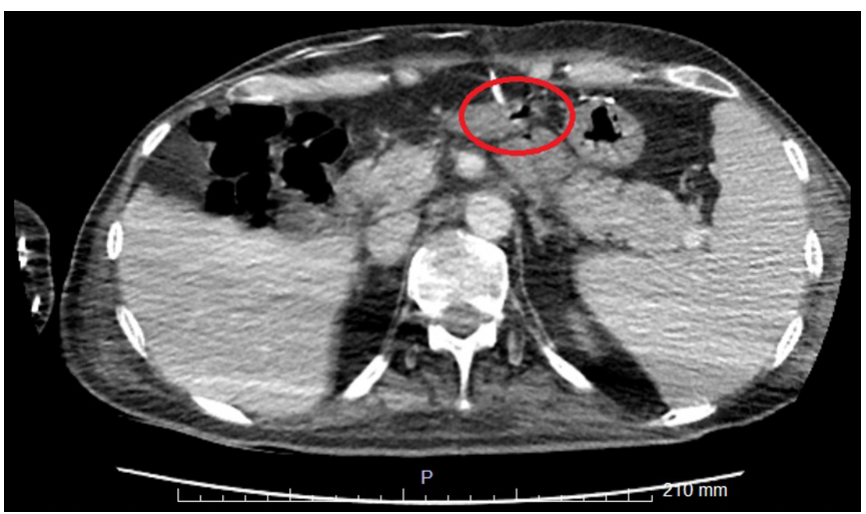

Figure 1. Computerized tomography image of the fistula area.

enteral nutrition was stopped and total parenteral nutrition was started instead, in order to follow the volume of the fistula. The fistula was considered as high-output during the follow-up (approximately $600 \mathrm{cc}$ per day) and surgery was planned since a spontaneous closure was not expected in the $2^{\text {nd }}$ week of follow-up. Fistulated area between stomach and colon was detected, partial resection was performed in stomach and colon was repaired with primary sutures. He was discharged uneventfully on the fourth postoperative day. He is being followed up for seven months with no further complaints. Written informed consent was obtained from the patient's legal guardian(s) for publication of this case report and any accompanying images.

\section{Discussion}

In the early eighties, PEG was introduced as an alternative option to the conventional surgical techniques for replacing gastrostomy tubes.

Most PEG procedures are performed for neurological disorders such as stroke or traumatic irreversible brain injury, and can also be applied due to anatomical problems such as cleft lip/palate surgery and head/neck injury. ${ }^{[1]}$

Percutaneous endoscopic gastrostomy can be performed under sedation without the need for general anesthesia with 95\% success in 15-30 minutes. However, some complications such as bleeding, hematoma, perforation, infection, wound maceration, gastrocolocutaneous fistula may occur with the rate of $17 \% .{ }^{[5]}$ The exact mechanism of gastrocolocutaneous fistula is not well known. However, the most reasonable theory is that the interposition of colon between the anterior abdominal wall and stomach. ${ }^{[6]}$ The leakage of gastric contents through the gastrocolic fistula into the colon leads to typical symptoms such as presence of diarrhea that contains nutri- tion products. The reverse condition causes feculent vomiting and the appearance of fecal material. ${ }^{[6]}$ This complication may be fatal, if it is not detected early and managed properly. ${ }^{[7]}$

Various techniques have been proposed to minimize the risk of colon penetration. Aspirating a saline-filled syringe before the endoscopic visualization in order to identify the interposing colon between the abdominal wall and stomach is one of these techniques which was suggested by Strodel et al. ${ }^{[8]} \mathrm{A}$ point to be avoided is that the excessive inflation of air into the stomach during the endoscopy which may cause the interposition of the transverse colon between the abdominal wall and the stomach. ${ }^{[9]}$ Ultrasound and/or CT scan can be considered in patients with complex abdominal anatomy. ${ }^{[10]}$ Techniques such as transillumination and continued finger pressure may be helpful for deciding the puncture site. When the gastrocolocutaneous fistula is suspected, upper GI endoscopy is recommended and water soluble contrast study or abdominal CT may also help to confirm the diagnosis. ${ }^{[11,12]}$

Historically, the key treatment for gastrocolocutaneous fistula was to allow the fistula to close after the feeding tube was removed. If the fistula does not close spontaneously, surgical repair should be performed by hybrid procedures (combination of endoscopy and laparoscopy) if possible, otherwise by laparotomy. ${ }^{[13]}$

\section{Conclusion}

In conclusion, PEG-associated complications are expected to increase along with the increasing requirement for PEG. Proper management of PEG complications enables early and effective recovery.

\section{Acknowledgments}

The authors thank all the general surgery staff for their cooperation. The authors have no conflict of interest and no financial issues to disclose. All the authors read and approved the paper.

\section{Disclosures}

Informed Consent: Written informed consent was obtained from the patient's legal guardian(s) for publication of this case report and any accompanying images.

Peer-review: Externally peer-reviewed.

Conflict of Interest: None declared. 


\section{References}

1. Rahnemai-Azar AA, Rahnemaiazar AA, Naghshizadian R, Kurtz A, Farkas DT. Percutaneous endoscopic gastrostomy: indications, technique, complications and management. World J Gastroenterol 2014;20:7739-51. [CrossRef]

2. Hucl T, Spicak J. Complications of percutaneous endoscopic gastrostomy. Best Pract Res Clin Gastroenterol 2016;30:769-81. [CrossRef]

3. Nunes G, Oliveira G, Cortez-Pinto J, Cruz J, Fonseca J. Gastrocolocutaneous fistula: An undetected complication of colon transfixation during percutaneous endoscopic gastrostomy. Turk J Gastroenterol 2018 Dec 12 [Epub ahead of print]. doi: 10.5152/tjg.2018.18552. [CrossRef]

4. Ruiz Ruiz JM, Rando Muñoz JF, Salvá Villar P, Lamarca Hurtado JC, Sánchez Molinero MD, Sanjurgo Molezun E, et al. Gastrocolocutaneous fistula: an uncommon complication of percutaneous endoscopicgastrostomy. [Article in Spanish]. Nutr Hosp 2012;27:306-9.

5. Smyth GP, McGreal GT, McDermott EW. Delayed presentation of a gastric colocutaneous fistula after percutaneous endoscopic gastrostomy. Nutrition 2003;19:905-6. [CrossRef]

6. Payne KM, King TM, Eisenach JB. The technique of percutaneous endoscopic gastrostomy. A safe and cost-effective al- ternative to operative gastrostomy. J Crit IIIn 1991;6:611-9.

7. Joo YJ, Koo JH, Song SH. Gastrocolic fistula as a cause of persistent diarrhea in a patient with a gastrostomy tube. Arch Phys Med Rehabil 2010;91:1790-2. [CrossRef]

8. Strodel WE, Lemmer J, Eckhauser F, Botham M, Dent T. Early experience with endoscopic percutaneous gastrostomy. Arch Surg 1983;118:449-53. [CrossRef]

9. Croaker GDH, Najmaldin AS. Laparoscopically assisted percutaneous endoscopic gastrostomy. Pediatr Surg Int 1997;12:130-1. [CrossRef]

10. Stefan MM, Holcomb GW 3rd, Ross AJ 3rd. Cologastric fistula as a complication of percutaneous endoscopic gastrostomy. JPEN J Parenter Enteral Nutr 1989;13:554-6. [CrossRef]

11. Kuriyama A. Gastrocolocutaneous Fistula due to Percutaneous Endoscopic Gastrostomy Placement. Intern Med 2016;55:3549. [CrossRef]

12. Kim HS, Bang CS, Kim YS, Kwon OK, Park MS, Eom JH, et al. Two cases of gastrocolocutaneous fistula with a long asymptomatic period afterpercutaneous endoscopic gastrostomy. Intest Res 2014;12:251-5. [CrossRef]

13. Lee J, Kim J, Kim HI, Oh CR, Choi S, Noh S, et al. Gastrocolocutaneous Fistula: An Unusual Case of Gastrostomy Tube Malfunction with Diarrhea. Clin Endosc 2018;51:196-200. 